\title{
ESTABELECIMENTO IN VITRO DE ÁPICES CAULINARES DE SUMAÚMA (Ceiba pentandra L. Gaertn)
}

\section{IN VITRO ESTABLISHMENT OF KAPOK TREE (Ceiba pentandra L. Gaertn) APICAL SHOOTS}

\author{
Perla Pimentel da SILVA ${ }^{1}$ \\ Luis Antônio Serrão CONTIM² \\ Danival Vieira de FREITAS ${ }^{3}$ \\ Paulo Henrique Rocha ARIDE ${ }^{4}$ \\ André Luis Wendt dos SANTOS
}

\section{RESUMO}

A sumaúma (Ceiba pentandra L. Gaertn) é uma espécie arbórea de grande importância para o setor florestal da Região Norte do Brasil. Apesar disso, ainda não existem relatos sobre o cultivo in vitro desta espécie. O presente trabalho teve como objetivo estabelecer um protocolo eficiente para assepsia e cultivo in vitro de ápices caulinares de sumaúma. Para isto foram avaliados os efeitos de diferentes agentes químicos ( $\mathrm{NaOCl}, \mathrm{HgCl}_{2}$ e $\mathrm{AgNO}_{3}$ ) para assepsia e estabelecimento in vitro de ápices caulinares. Diferentes tipos e concentrações de citocininas (BAP, CIN e TDZ) foram testados durante o enraizamento, alongamento e indução de brotos. Apesar das dificuldades usualmente associadas ao estabelecimento e cultivo in vitro de espécies arbóreas, os resultados obtidos não evidenciaram problemas na manipulação in vitro de sumaúma.

Palavras-chave: citocininas; enraizamento; micropropagação.

\begin{abstract}
The kapok tree (Ceiba pentandra L. Gaertn) is a forest species with high importance to the forest sector in North of Brazil. Despite of that, there are no reports about the in vitro culture of this species. The aim of this work was the development of a reliable protocol for disinfestation and in vitro culture of apical shoots of kapok tree. There were tested different chemical compounds $\left(\mathrm{NaOCl}, \mathrm{HgCl}_{2}\right.$ e $\mathrm{AgNO}_{3}$ ) for apical shoot disinfestation and in vitro establishment. Different types and concentrations of citokinins (BAP, CIN e TDZ) were tested during apical shoot rooting, elongation, and bud induction. Although forest species are normally considered difficult to establish and cultivated in vitro, the kapok tree did not show problems during in vitro manipulation.
\end{abstract}

Key-words: citokinins; rooting; micropropagation.

${ }^{1}$ Bióloga, Mestranda do curso de Mestrado Acadêmico em Biologia Urbana, Centro Universitário Nilton Lins, bolsista de FAPEAM/AM, Manaus, AM, Brasil. E-mail:ppspimentel@hotmail.com

${ }^{2}$ Engenherio Agrônomo, Dr., Universidade Federal de Goiás, professor adjunto, Jataí, Go, Brasil. E-mail: Icontim@pq.cnpq.br

${ }^{3}$ Engenheiro Florestal, Msc, Centro Universitário Nilton Lins, professor principal, Manaus, AM, Brasil. E-mail: dfreitas@niltonlins.br

${ }^{4}$ Biólogo, Dr., Centro Universitário Nilton Lins, professor principal, Manaus, AM, Brasil. E-mail: paride@niltonlins.br

${ }^{5}$ Engenhoerio Florestal, Dr., Centro Universitário Nilton Lins, professor principal, Manaus, AM, Brasil. E-mail: alwsantos@yahoo.com.br 
SILVA, P. P. et al. Estabelecimento in vitro de ápices...

\section{INTRODUÇÃO}

A sumaúma (Ceiba pentandra L. Gaertn) é uma espécie arbórea de Bombaceae. Considerada a maior árvore da Amazônia, apresenta distribuição pantropical, ocorrendo em solos argilosos das florestas de terra firme, áreas inundadas ou pantanosas das várzeas da Bacia Amazônica. Devido à alta qualidade da sua madeira para a indústria de laminados, a sumaúma tem sido intensivamente explorada ao longo das últimas décadas, acarretando processos de erosão genética, haja vista que estão sendo extraídos os melhores genótipos das populações naturais (Hummel, 1997; Jansen, 1995). Não obstante a fenologia irregular, o comportamento recalcitrante da semente e a alta demanda por luminosidade ao longo do seu ciclo de vida dificultam ainda mais o processo de regeneração natural desta espécie (Loureiro et al., 2000; Sampaio,1999). Deste modo, programas que contemplem o melhoramento genético e a reposição ao ambiente natural de genótipos elite e/ou raros de sumaúma são bastante desejáveis.

Técnicas baseadas na biotecnologia proporcionam métodos eficientes e de baixo custo para micropropagação, conservação e melhoramento genético de espécies arbóreas (Guerra et al., 2000; dos Santos et al., 2008). A micropropagação de plantas, mais especificamente o cultivo de ápices caulinares, tem sido amplamente utilizada para a clonagem e a conservação ex situ de espécies arbóreas tropicais (Lopes et al., 2001; Noleto \& Silveira, 2004; Handa et al., 2005). Adicionalmente, na maioria dos casos, o cultivo in vitro de ápices caulinares proporciona a manutenção da identidade do genótipo regenerado, devido à estabilidade das células do meristema caulinar (Torres et al.,1998).

Contudo, para que esta técnica possa ser associada a programas de melhoramento genético e de conservação de espécies arbóreas tropicais, é necessário 0 desenvolvimento de protocolos eficientes que permitam o estabelecimento e o desenvolvimento de um grande número de explantes in vitro. Com freqüência, os maiores desafios à aplicação das técnicas de cultivo in vitro, principalmente em espécies arbóreas, são a contaminação endógena e exógena por microorganismos e a oxidação fenólica (Skirvin et al., 1999; George, 1993). A seleção de explantes com maior vigor, a diminuição do tempo de manipulação do material vegetal e, principalmente, a imersão dos explantes em agentes desinfestantes são as abordagens usualmente utilizadas durante o estabelecimento de protocolos de assepsia do material vegetal (Skirvin et al., 1999).

O presente trabalho teve como objetivo estabelecer um protocolo eficiente para assepsia e estabelecimento in vitro de ápices caulinares de sumaúma. Diferentes agentes desinfestantes, antioxidantes, bem como a sua concentração e tempo de exposição aos ápices caulinares foram avaliados. Adicionalmente, a influência de diferentes citocininas, benzilaminopurina (BAP), cinetina (CIN) e thidiazuron (TDZ) no processo de alongamento, formação de brotos e enraizamento foi avaliada. Nosso trabalho representa o primeiro esforço para o estabelecimento in vitro de sumaúma.

\section{MATERIAL E MÉTODOS}

\section{Material vegetal e obtenção dos explantes}

Os experimentos foram conduzidos no Viveiro Florestal e no Laboratório de Biotecnologia Vegetal (LBV) do Centro Universitário Nilton Lins, Manaus, AM. Mudas de sumaúma foram estabelecidas no viveiro florestal a partir de sementes oriundas de Belém, PA. A semeadura foi realizada em tubetes plásticos (T-280: diâmetro externo $63 \mathrm{~mm}$ x diâmetro interno $52 \mathrm{~mm}$ x altura $190 \mathrm{~mm}$, capacidade $280 \mathrm{~cm}^{3}$ ) contendo uma mistura de terra vegetal, serragem e cama de aviário na proporção de $2: 5: 3$, respectivamente. Após a germinação, ocorrida em aproximadamente sete dias, às plântulas foram transferidas para vasos com capacidade de $2 \mathrm{~kg}$, contendo mesmo substrato utilizado para germinação suplementado com $1,15 \mathrm{~g}$ de superfosfato triplo, $0,35 \mathrm{~g}$ de $\mathrm{KCl}$ e $0,35 \mathrm{~g}$ de uréia para cada $2 \mathrm{~kg}$ de mistura. Após cinco meses de cultivo no viveiro, as mudas de sumaúma apresentando altura entre 20 e $40 \mathrm{~cm}$ e bom estado fitossanitário foram selecionadas para obtenção dos ápices caulinares $(15-20 \mathrm{~mm})$. Após a retirada, os ápices caulinares foram imersos em água destilada autoclavada contendo $3 \mathrm{~g} \mathrm{dm}^{-3}$ de polivinilpirrolidona (PVP) e em seguida transportados para o LBV para realização dos testes de assepsia e cultivo in vitro.

\section{Testes de assepsia e cultivo in vitro do material vegetal}

Para os testes de assepsia, os ápices caulinares de sumaúma foram inicialmente imersos em solução de álcool etílico $70 \%(\mathrm{v} / \mathrm{v})$ por $1 \mathrm{~min}$. Em seguida os ápices foram submetidos por $10 \mathrm{~min}$ aos seguintes tratamentos: a) solução de $\mathrm{NaOCl}(2$ $-2,5 \%$ de cloro ativo) nas concentrações de $2,5,5$, 10,25 e $50 \%$ (v/v); b) solução de $\mathrm{HgCl}_{2}$ a $0,1,0,25$ e $0,5 \%(\mathrm{p} / \mathrm{v})$; e c) solução de $\mathrm{AgNO}_{3}$ a $0,1,0,25$ e $0,5 \%(\mathrm{p} / \mathrm{v})$. Todas as soluções testadas receberam três gotas de Tween 20 por $100 \mathrm{~cm}^{3}$ de solução. Em seguida, os ápices caulinares foram lavados três vezes com água destilada autoclavada em fluxo laminar. Para cada tratamento foram utilizadas 15 repetições, sendo cada repetição composta por um ápice em tubo de ensaio $(25 \times 150 \mathrm{~mm})$ contendo $10 \mathrm{~cm}^{3}$ de meio de cultura MS (Murashige \& Skoog, 1962), suplementado com $3 \%(\mathrm{p} / \mathrm{v})$ de sacarose e $0,65 \%(\mathrm{p} / \mathrm{v})$ de agar $\left(\mathrm{Vetec}^{\circledR}\right)$. O controle negativo foi lavado em água destilada autoclavada contendo três gotas por $100 \mathrm{~cm}^{3}$ de Tween $20 . \mathrm{O}$ pH do meio foi ajustado para 5,8 com $\mathrm{NaOH}$ e $\mathrm{HCl}$ e autoclavado a $120{ }^{\circ} \mathrm{C}$ por $15 \mathrm{~min}$. Após a transferência para condições in vitro, os ápices foram mantidos a $26 \pm 2{ }^{\circ} \mathrm{C}$, com fotoperíodo de $16 / 8$ h (claro/escuro) sob lâmpadas fluorescentes 
SILVA, P. P. et al. Estabelecimento in vitro de ápices...

fornecendo $25,2 \mu \mathrm{M} \mathrm{m}^{-2} \mathrm{~s}^{-1}$ de irradiância. Foram feitas observações do material a cada cinco dias, e ao final de 30 dias foi feita a determinação o número total de explantes oxidados, contaminados ou estabelecidos.

Avaliação do uso de citocininas (BAP, CIN e TDZ) para indução de brotos, enraizamento e alongamento dos ápices caulinares

Definido o melhor tratamento para assepsia, foi avaliada a influência de citocininas no processo de indução de brotos, enraizamento e alongamento dos ápices caulinares. Utilizou-se como meio de cultura básico a mesma composição daquele usado nos testes de assepsia, porém com a suplementação independente das citocininas cinetina (CIN), thiadizuron (TDZ) e benzilaminopurina (BAP), nas concentrações; 0,02; 0,$22 ; 2,2$ e $4,4 \mathrm{mg} \mathrm{dm}^{-3}$. Considerou-se como controle os ápices caulinares mantidos em meio de cultura não adicionado de citocininas. A avaliação da resposta às citocininas (número de brotos, alongamento e número de ápices enraizados) foi realizada após 45 dias de cultivo. Para cada tratamento foram utilizadas 15 repetições, cada uma constando de um ápice para cada tubo de ensaio $(25 \times 150 \mathrm{~mm})$, contendo $10 \mathrm{~cm}^{3}$ de meio de cultura.

\section{Análises estatísticas}

Em todos os experimentos foi utilizado o delineamento experimental inteiramente casualizado. No experimento com citocininas foi feito um arranjo fatorial de $3 \times 5$ (três classes de hormônios por cinco concentrações). Para os experimentos de assepsia e com uso de citocininas os dados foram transformados em $(x+1)^{1 / 2}$ para a realização da análise de variância (ANOVA). As médias das porcentagens dos experimentos de assepsia e do uso de citocininas foram comparadas pelo teste de Tukey a $5 \%$ de probabilidade.

\section{RESULTADOS E DISCUSSÃO}

Avaliação do efeito dos agentes desinfestantes sobre os ápices caulinares

Os ápices caulinares submetidos aos diferentes tratamentos para assepsia apresentaram diferenças significativas quanto à eficiência de desinfestação, em relação à porcentagem de explantes contaminados, oxidados e estabelecidos in vitro (Tabela 1). As menores taxas de contaminação dos explantes foram observadas nos tratamentos com a utilização de $0,25 \%$ e $0,5 \%(\mathrm{p} / \mathrm{v})$ de $\mathrm{HgCl}_{2}$ e $0,1 \%$ e $0,25 \%$ (p/v) de $\mathrm{AgNO}_{3}$. Apesar de amplamente utilizado para assepsia de explantes vegetais (Picolotto et al., 2007; Donini et al., 2008), o tratamento com $\mathrm{NaOCl}$ não apresentou resultados satisfatórios para o estabelecimento dos ápices caulinares nas concentrações testadas $(2,5-$ $50 \%(\mathrm{v} / \mathrm{v}))$, resultando na contaminação de todos os explantes introduzidos in vitro. $O$ sucesso da assepsia depende da idade e do tipo de explante, da concentração da solução esterilizante e do tempo de exposição do explante à solução (Donini et al., 2005). E ainda, as concentrações das soluções esterilizantes podem variar em função da sensibilidade do tecido a ser desinfestado (Grattapaglia \& Machado, 1998).

TABELA 1 - Porcentagem média de contaminação, oxidação e estabelecimento in vitro de ápices caulinares de sumaúma, após assepsia em diferentes concentrações de $\mathrm{HgCl}_{2}, \mathrm{AgNO}_{3}$ e $\mathrm{NaOCl}$.

\begin{tabular}{|c|c|c|c|c|c|}
\hline Tratamento & $\begin{array}{c}\text { Agente } \\
\text { Desinfestante }\end{array}$ & $\begin{array}{c}\text { Concentração } \\
(\%)\end{array}$ & $\begin{array}{c}\text { Contaminação } \\
(\%)\end{array}$ & $\begin{array}{c}\text { Oxidação } \\
(\%)\end{array}$ & $\begin{array}{c}\text { Sobrevivência } \\
\text { (\%) }\end{array}$ \\
\hline 1 & \multirow{3}{*}{$\mathrm{HgCl}_{2}$} & 0,1 & $69,68 \mathrm{bc}$ & $89,90 \mathrm{c}$ & $30,31 \mathrm{c}$ \\
\hline 2 & & 0,25 & $9,07 \mathrm{a}$ & $19,17 \mathrm{a}$ & 90,92 a \\
\hline 3 & & 0,5 & $19,17 \mathrm{a}$ & $49,48 a b$ & $82,85 \mathrm{a}$ \\
\hline 4 & \multirow{3}{*}{$\mathrm{AgNO}_{3}$} & 0,1 & $29,29 a$ & $54,53 \mathrm{~b}$ & 70,70 a \\
\hline 5 & & 0,25 & $14,12 \mathrm{a}$ & $39,39 a b$ & 85,87 a \\
\hline 6 & & 0,5 & $64,63 \mathrm{~b}$ & $69,68 \mathrm{bc}$ & $35,36 \mathrm{~b}$ \\
\hline 7 & \multirow{5}{*}{$\mathrm{NaOCl}$} & 2,5 & $100 \mathrm{c}$ & $100 \mathrm{c}$ & $0,00 \mathrm{c}$ \\
\hline 8 & & 5 & $100 \mathrm{c}$ & $100 \mathrm{c}$ & $0,00 \mathrm{c}$ \\
\hline 9 & & 10 & $100 \mathrm{c}$ & $100 \mathrm{c}$ & $0,00 \mathrm{c}$ \\
\hline 10 & & 25 & $100 \mathrm{c}$ & $100 \mathrm{c}$ & $0,00 \mathrm{c}$ \\
\hline 11 & & 50 & $100 \mathrm{c}$ & $100 \mathrm{c}$ & $0,00 \mathrm{c}$ \\
\hline 12 & Controle & 0 & $100 \mathrm{c}$ & $100 \mathrm{c}$ & $0,00 \mathrm{c}$ \\
\hline
\end{tabular}

Valores seguidos de mesma letra nas colunas não diferem estatisticamente entre si, pelo teste de Tukey, em $5 \%$ de probabilidade. $\mathrm{CV}=$ coeficiente de variação. 
SILVA, P. P. et al. Estabelecimento in vitro de ápices...

Entre os ápices caulinares estabelecidos in vitro, não foram observadas diferenças significativas entre os tratamentos com $\mathrm{HgCl}_{2}(0,25$ e $0,5 \%)$ e $\mathrm{AgNO}_{3} \quad(0,1$ e $0,25 \%)$. Os tratamentos que propiciaram maior índice de sobrevivência, considerando simultaneamente menores taxas de oxidação e contaminação, foram obtidos com o uso de $0,25 \%(\mathrm{p} / \mathrm{v}) \mathrm{HgCl}_{2}$ e $0,25 \%(\mathrm{p} / \mathrm{v}) \mathrm{AgNO}_{3}$.

Apesar da alta eficiência do $\mathrm{HgCl}_{2}$ no processo de assepsia de explantes de espécies arbóreas (Ribas et al., 2003), trata-se de um produto tóxico ao ambiente (George, 1993). Neste contexto, apesar dos melhores resultados de assepsia com sumaúma terem sido obtidos com $0,25 \%(\mathrm{p} / \mathrm{v}) \mathrm{HgCl}_{2}$, consideramos a utilização de $0,25 \%(\mathrm{p} / \mathrm{v}) \mathrm{AgNO}_{3}$ como procedimento padrão para a assepsia de ápices caulinares de sumaúma. De modo semelhante, Han et al. (2000) obtiveram 85\% de rizomas assépticos em Epimedium koreanum utilizando $0,1 \%$ de $\mathrm{AgNO}_{3}$. Resultados semelhantes (sobrevivência de 60\%) foram obtidos em segmentos nodais de Rosa $x$ hybrida CV. VEGAS, utilizando $\mathrm{AgNO}_{3}$ a 0,1\% (Drefahl, 2004).

Os melhores resultados para o controle da oxidação fenólica foram observadas nos tratamentos com $\mathrm{HgCl}_{2}(0,25 \%)$ e $\mathrm{AgNO}_{3}(0,1$ e 0,25\%). Segundo Mônaco et al. (1977), a oxidação fenólica pode dificultar o estabelecimento inicial do material sob condições in vitro, devido à formação de quinonas, que causam a inibição do crescimento e a morte dos explantes. De acordo com Andrade \& Lacerda (2000), o acúmulo de polifenóis em torno da superfície incisada também pode dificultar e até impedir totalmente o estabelecimento dos explantes in vitro. Os polifenóis são acumulados ao redor da superfície incisada, modificando a composição do meio de cultivo e a absorção de nutrientes.

Avaliação do efeito das citocininas BAP, CIN e TDZ no enraizamento, alongamento e formação de brotos nos ápices caulinares

As citocininas exercem diferentes efeitos sobre a fisiologia do desenvolvimento em plantas. São associados à presença desta classe de hormônios eventos como a formação de brotações a partir do meristema apical, expansão foliar, retardo da senescência, promoção da germinação de sementes e formação de cloroplastos (Taiz \& Zeiger, 2008; Mok \& Mok, 2001). Em condições in vitro, as citocininas participam de processos de regulação da divisão, crescimento e diferenciação celular. Durante o enraizamento de ápices caulinares, geralmente são utilizadas em baixas concentrações, sendo o BAP e a $\mathrm{CIN}$ as mais utilizadas (Assis \& Teixeira, 1998).

As melhores respostas dos ápices de sumaúma para o enraizamento in vitro (Tabela 2) foram obtidas com a utilização da citocinina BAP, na concentração de $0.22 \mathrm{mg} \mathrm{dm}^{-3}(53,33 \%)$, observada após 25 dias de tratamento (Figura C). Em Phoenix dactylifera, o uso de $2.0 \mathrm{mg} \mathrm{dm}^{-3}$ de BAP em combinação com $2.0 \mathrm{mg} \mathrm{dm}^{-3}$ de AIA resultou no enraizamento de $33,3 \%$ das brotações estabelecidas in vitro (Costa \& Aloufa, 2006).

TABELA 2 - Porcentagem média de enraizamento de ápices caulinares de sumaúma, após 45 dias de cultivo em meio de cultura MS suplementado com diferentes concentrações de cinetina (CIN), benzillaminopurina (BAP) e thidiazuron (TDZ).

\begin{tabular}{llllrrr}
\hline \multirow{2}{*}{ Hormônio } & \multicolumn{7}{c}{ Concentração $\left(\mathrm{mg} \mathrm{dm}^{-3}\right)$} \\
\cline { 2 - 7 } & 0 & 0,02 & 0,22 & 2,20 & 4,40 \\
\hline CIN & 0 & $\mathrm{Aa}$ & $0 \mathrm{Aa}$ & $0 \mathrm{Ba}$ & $13,3 \mathrm{Aa}$ & 0 \\
BAP & $0 \mathrm{Ab}$ & $0 \mathrm{Ab}$ & $53,3 \mathrm{Aa}$ & $20 \mathrm{Ab}$ & 0 \\
TDZ & $0 \mathrm{Aa}$ & $0 \mathrm{Aa}$ & $0 \mathrm{Ba}$ & $0 \mathrm{Aa}$ & $0 \mathrm{Aa}$ \\
\hline
\end{tabular}

$\mathrm{CV}_{\text {(concentraçã) }}=1,39 \%$

Valores seguidos pela mesma letra maiúscula na vertical (citocinina) não diferem estatisticamente entre si. Valores seguidos pela mesma letra minúscula na horizontal (concentração de citocinina) não diferem estatisticamente entre si pelo teste de Tukey, em $5 \%$ de probabilidade. CV = coeficiente de variação.

Em contraste com os resultados observados com adição de BAP, os tratamentos com as duas outras citocininas avaliadas, CIN e TDZ, mostraram-se ineficientes para a indução do processo de enraizamento dos ápices caulinares de sumaúma nas concentrações utilizadas. Resultados semelhantes foram obtidos em Linium sp. com o uso do TDZ (Mundhara \& Rashid, 2006) e com o uso da CIN em explantes de Glycine max (L) Merril (Diniz et al., 1991).

O mecanismo de iniciação radicular em tecidos caulinares, principalmente no aspecto da fisiologia da diferenciação, é ainda pouco compreendido, pois os reguladores de crescimento apresentam efeitos diversos no metabolismo, no crescimento e na diferenciação, afetando outros processos fisiológicos (Assis \& Teixeira, 1998).

Após 45 dias de cultivo, a melhor resposta quanto ao alongamento dos ápices se deu no tratamento controle $(80 \%)$, seguido dos materiais cultivados na presença dos reguladores CIN e BAP nas concentrações de $0,02 \mathrm{mg} \mathrm{dm}^{-3}$ e $2,20 \mathrm{mg} \mathrm{dm}^{-3}$, ambos apresentando taxa de 60\% (Tabela 3). 
SILVA, P. P. et al. Estabelecimento in vitro de ápices...

TABELA 3 - Porcentagem média de alongamento de ápices caulinares de sumaúma, após 45 dias de cultivo em meio de cultura MS suplementado com diferentes concentrações de cinetina (CIN), benzilaminopurina (BAP) e thidiazuron (TDZ).

\begin{tabular}{lrrrrrr}
\hline \multirow{2}{*}{ Hormônio } & \multicolumn{7}{c}{ Concentração $\left(\mathrm{mg} \mathrm{dm}^{-3}\right)$} \\
\cline { 2 - 7 } & \multicolumn{10}{c}{0,02} & 0,22 & 2,20 & 4,40 \\
\hline CIN & $33,3 \mathrm{Aa}$ & $60 \mathrm{Aa}$ & $20 \mathrm{Aa}$ & $60 \mathrm{Aa}$ & $20 \mathrm{Aa}$ \\
BAP & $80 \mathrm{Aa}$ & $0 \mathrm{Bb}$ & $33,3 \mathrm{Aa}$ & $53,3 \mathrm{Aa}$ & $26,7 \mathrm{Aa}$ \\
TDZ & $40 \mathrm{Aa}$ & $46,7 \mathrm{Aa}$ & $20 \mathrm{Aa}$ & $13,3 \mathrm{Aa}$ & $6,7 \mathrm{Aa}$ \\
\hline
\end{tabular}

$\mathrm{CV}_{\text {(concentração) }}=0,53 \%$

Valores seguidos pela mesma letra maiúscula na vertical (citocinina) não diferem estatisticamente entre si. Valores seguidos pela mesma letra minúscula na horizontal (concentração de citocinina) não diferem estatisticamente entre si pelo teste de Tukey, em $5 \%$ de probabilidade. CV = coeficiente de variação.

Adicionalmente, os tratamentos contendo os reguladores CIN e BAP, nas concentrações de $0,02 \mathrm{mg} \mathrm{dm}^{-3}$ e $2,20 \mathrm{mg} \mathrm{dm}^{-3}$, mostraram resultados mais efetivos para a indução do alongamento dos ápices, com taxas de alongamentos entre $60 \%$ e $80 \%$ respectivamente (Tabela 3 ). A eficiência da CIN no alongamento de ápices também foi descrita para Carthamus tinctorius L. (Radhika et al., 2006). De maneira similar ao observado nos testes para enraizamento, o TDZ mostrou-se ineficiente para a indução do alongamento dos ápices caulinares de sumaúma. Em Fragaria $\times$ ananassa Duch. o uso do $\operatorname{TDZ}\left(0,11-0,88 \mathrm{mg} \mathrm{dm}^{-3}\right)$ promoveu a formação de calos e a supressão do alongamento de brotos (Debnath, 2005). Em Impatiens walleriana brotações inoculadas na presença de TDZ $(0,002$ -
$0,22 \mathrm{mg} \mathrm{dm}^{-3}$ ) provocaram a redução no alongamento dos ápices e um alargamento da base (Subotié et al., 2008).

Com exceção do tratamento contendo 0,22 $\mathrm{mg} \mathrm{dm}^{-3}$ de BAP, não foram observadas diferenças significativas na formação de brotos nos ápices caulinares de sumaúma (Tabela 4; Figura 1D). Apesar dos inúmeros relatos sobre a importância do uso de citocininas na indução de brotos in vitro (Morre et al., 1998; Ghu \& Ribeiro, 2002; Kielse et al., 2009; Rocha et al., 2009) a maior taxa de formação de brotos foi obtida no tratamento controle, sugerindo que fatores como o estresse provocado pelo cultivo in vitro ou então a produções endógena de hormônios já seriam suficientes para a indução de brotos em sumaúma.

TABELA 4 - Porcentagem média de brotos induzidos a partir de ápices caulinares de sumaúma, após 45 dias de cultivo em meio de cultura MS suplementado com diferentes concentrações de cinetina (CIN), benzilaminopurina (BAP) e thidiazuron (TDZ).

\begin{tabular}{lccccccc}
\hline \multirow{2}{*}{ Hormônio } & \multicolumn{7}{c}{ Concentração $\left(\mathrm{mg} \mathrm{dm}^{-3}\right)$} \\
\cline { 2 - 7 } & 0 & 0.02 & 0.22 & 2.20 & 4.40 \\
\hline CIN & $2,13 \mathrm{Aa}$ & $2,47 \mathrm{Aa}$ & $0,87 \mathrm{Aa}$ & $2,13 \mathrm{Aa}$ & $0,73 \mathrm{Aa}$ \\
BAP & $2,73 \mathrm{Aa}$ & $0,00 \mathrm{Bb}$ & $1,40 \mathrm{Aa}$ & $2,07 \mathrm{Aa}$ & $1,00 \mathrm{Aa}$ \\
TDZ & $1,20 \mathrm{Aa}$ & $1,60 \mathrm{Aa}$ & $0,67 \mathrm{Aa}$ & $0,60 \mathrm{Aa}$ & $0,20 \mathrm{Aa}$ \\
\hline
\end{tabular}

$\mathrm{CV}_{\text {(concentração) }}=1,40 \%$

Valores seguidos pela mesma letra maiúscula na vertical (citocinina) não diferem estatisticamente entre si. Valores seguidos pela mesma letra minúscula na horizontal (concentração de citocinina) não diferem estatisticamente entre si pelo teste de Tukey, em $5 \%$ de probabilidade. CV = coeficiente de variação.

\section{CONCLUSÕES}

Apesar das dificuldades usualmente associadas ao cultivo in vitro de espécies arbóreas, foi possível o estabelecimento e indução de morfogênese a partir de ápices caulinares de sumaúma. Os resultados apresentados no presente trabalho são inéditos para esta espécie e podem direcionar futuros estudos sobre a regeneração in vitro de sumaúma.

\section{AGRADECIMENTOS}

Os autores gostariam de agradecer a Fundação de Amparo a Pesquisa do Estado do Amazonas (FAPEAM) pela bolsa de mestrado concedida a Perla S. Pimentel, ao CNPq/CTAmazônia pelo financiamento do trabalho e ao programa de Pós-Graduação em Biologia Urbana do Centro Universitário Nilton Lins (CUNL) pelo apoio concedido durante a realização dos experimentos. 
SILVA, P. P. et al. Estabelecimento in vitro de ápices...

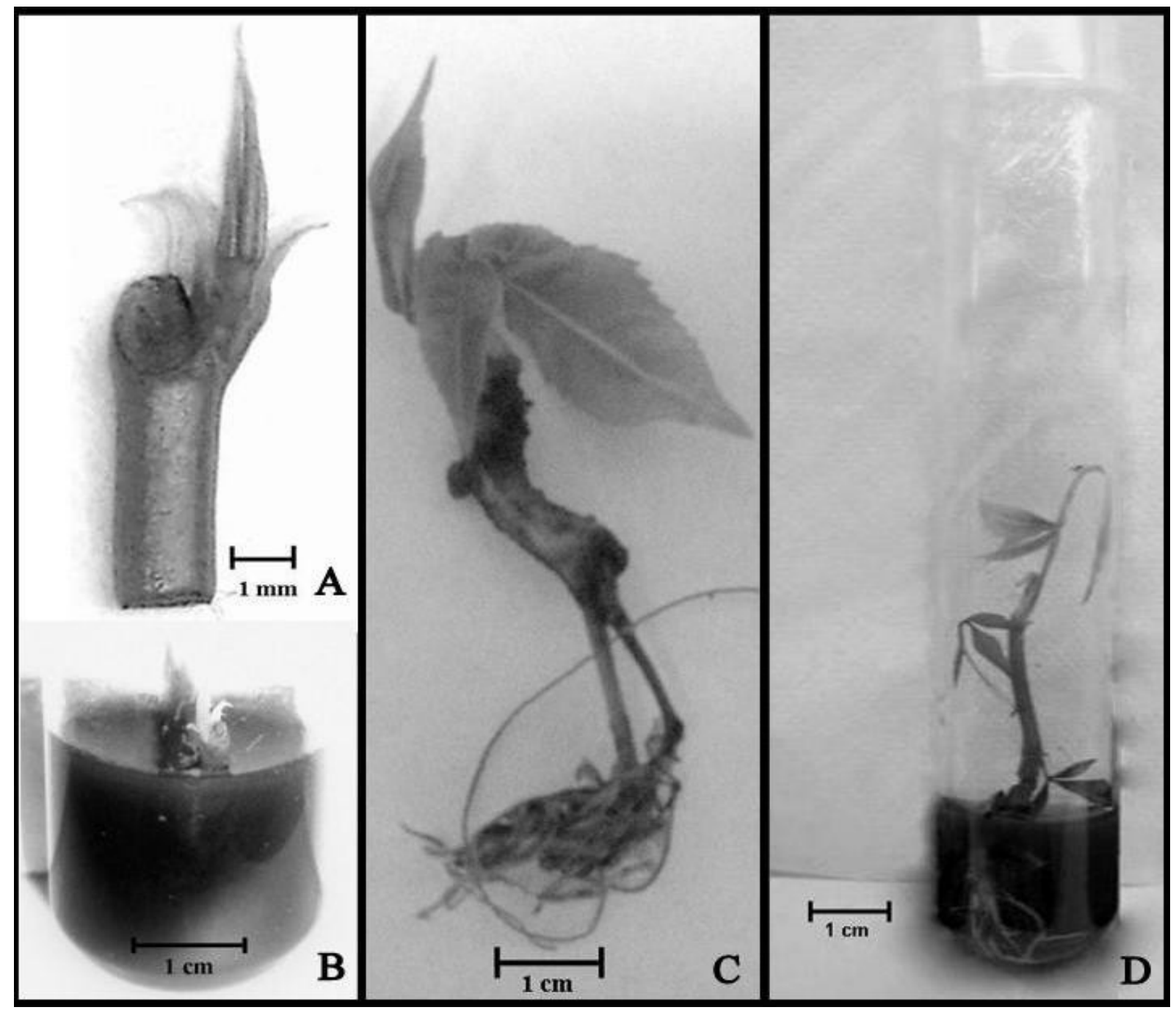

FIGURA 1 - A) ápice isolado; B) ápice recém-transferido in vitro; C) enraizamento de ápice após vinte dias da transferência in vitro com uso de $0,22 \mathrm{mg} \mathrm{dm}^{-3}$ de benzilaminopurina (BAP); D) brotações foliares com uso de $2,20 \mathrm{mg} \mathrm{dm}^{-3}$ cinetina (CIN) após 20 dias da transferência in vitro.

\section{REFERÊNCIAS}

1. ANDRADE, M. W.; LACERDA, M. Q. L. Micropropagação de aroeira (Myracrodrun urundeuva Fr. Allemao). Ciência e Agrotecnologia, v. 24, n.1, p.174-180, 2000

2. ASSIS, T.F.; TEIXEIRA, S.L. Enraizamento de plantas lenhosas. In: TORRES, A.C.; CALDAS, L.S.; BUSO, J.A. (Ed.) Cultura de tecidos e transformação genética de plantas. Brasília: EMBRAPA, 1998, p. 261-296.

3. COSTA, N. M. S; ALOUFA, M. A. I. Organogênese direta de Phoenix dactylifera L. via pecíolo cotiledonar. Pesquisa Agropecuária Tropical, v. 36, n. 3, p.195-198, 2006.

4. DEBNATH, S. C. Strawberry sepal: another explant for thidiazuron-induced adventitious shoot regeneration. In Vitro Cellular and Developmental Biology - Plant, v. 41, n. 5, p. 671-676. 2005.

5. DINIZ, J. D. N. et al. Influencia do ácido naftaleacético e cinetina no crescimento e diferenciação de tecidos de soja in vitro. Pesquisa Agropecuária Brasileira, v. 26, n. 11/12, p. 1925-1930. 1991.

6. DONINI, L. P. et al. Preparo de lâminas foliares de aráceas ornamentais: desinfestação com diferentes concentrações de hipoclorito de sódio. Arquivos do Instituto Biológico de São Paulo, v. 72, n. 4, p. 517-522, 2005.

7. DONINI, L. P. et al. Avaliação da resposta de três cultivares de oliveira ao cultivo in vitro sob diferentes comprimentos de onda luminosa e efeitos da combinação de zeatina e ácido giberélico. Scientia Agraria, v. 9, n. 2, p. 229-233, 2008.

8. DOS SANTOS, A. L. W. et al. Somatic embryogenesis in Araucaria angustifolia. Biologia Plantarum, v. 52, n. 1, p. 195199, 2008.

9. DREFAHL, A. Organogênese de Rosa $x$ hybrida CV. VEGAS. 2004. 88 f. Dissertação (Mestrado em Ciências Agronômicas-Produção vegetal)-Curso de Pós-Graduação em Agronomia, Setor de Ciências Agrárias, Universidade Federal do Paraná, Curitiba, 2004.

10. GRATTAPLAGLIA, D.; MACHADO, M. A. Micropropagação. In: TORRES, A. C.; CALDAS, L. S., BUSO, J. A. (Ed.) Cultura de tecidos e transformação genética de plantas. Brasília: EMBRAPA, 1998. p.183-260.

11. GEORGE, E. F. Plant propagation by tissue culture: the technology. Wiltshire: Exegetics Limited, 1993. 574 p. 
SILVA, P. P. et al. Estabelecimento in vitro de ápices...

12. GUERRA, M. P. et al. Somatic embryogenesis in Araucaria angustifolia. In: JAIN, S.M.; GUPTA, P.K.; NEWTON, R.J. (Ed.). Somatic embryogenesis in woody plants. Dordrecht: Kluwer Academic Publishers, 2000. v. 6. p. 457-478.

13. GHU, E. P.; RIBEIRO, R. C. L. F. Growth and carbohydrate changes in shoot cultures of Dioscorea species as influenced by photoperiod, exogenous sucrose and cytokinin concentrations. Plant Cell, Tissue and Organ Culture, v. 70, n. 3, p. 241-249, 2002.

14. HAN, I. et al. In vitro plant regeneration for mass propagation of Epimedium koreanum $\mathrm{N}$. Korean Journal of Horticultural Science and Technology, v. 6, n. 18, p. 834-838, 2000.

15. HANDA, L. et al. Cultura in vitro de embriões e de gemas de mudas de pau-rosa (Aniba rosaeodora Ducke). Acta Amazônica, v. 35, n. 1, p. 29-33, 2005.

16. HUMMEL, A. C. Diagnóstico do subsetor madeireiro do Estado do Amazonas. Manaus: SEBRAE, 1997. 76 p. (Série Estudos Setoriais).

17. JANSEN, M. R. A. Comportamento de seis progênies de sumaúma Ceiba pentandra L. Gaertn, plantadas em solos de terra firme na Amazônia Central. 1995. 85 f. Dissertação (Mestrado em Ciências de Florestas Tropicais)Curso de Pós-Graduação em Biologia Tropical e Recursos Naturais, Coordenação de Pós-Graduação, Instituto Naciona de pesquisas da Amazônia/Universidade Federal do Amazonas, Manaus, 1995.

18. KIELSE, P. et al. Regeneração in vitro de Parapiptadenia rígida. Ciência Rural, v. 39, n. 4, p. 1098-1104, 2009

19. LOPES, S. C. L. et al. Enraizamento in vitro de mogno (Swietenia macrophylla King). Cerne, v. 7, n. 1, p. 124-128, 2001.

20. LOUREIRO, A. A. et al. Essências madeireiras da Amazônia. Manaus: MCT/INPA-CPPF, 2000. 191 p.

21. MONACO, L. C. et al. Applications of tissue culture in the improvement of coffee. In: REINERT, J.; BAJAJ, Y.P.S. de (Eds.). Applied and fundamental aspects of plant cell, tissue, and organ culture. Berlin: Springer-Verlag, 1977. p. 109-126.

22. MORRE, J. L. et al. Multiple shoot induction and plant regeneration from embryonic axes of cotton. Plant Cell, and Organ Culture, v. 54, n. 3, p.131-136, 1998.

23. MOK, D. W. S.; MOK, M. C. Cytokinin metabolism and action. Annual Review of Plant Physiology and Plant Molecular Biology, v. 52, p. 89-118, 2001.

24. MUNDHARA, R.; RASHID, A. TDZ-induced triple-response and shoot formation on intact seedlings of Linum, putative role of ethylene in regeneration. Plant Science, v. 170, n. 2, p.185-190, 2006.

25. MURASHIGE T; SKOOG S. A revised medium for rapid growth and bio-assays with tobacco tissue cultures. Physiologia Plantarum, v. 15, n. 1, p. 437-496, 1962.

26. NOLETO, L. G.; SILVEIRA, C. E. S. Micropropagação de copaíba. Revista Biotecnologia Ciência \& Desenvolvimento, v. 33, n. 2, p. 109-120, 2004.

27. PICOLOTTO, L. et al. Efeito do hipoclorito de sódio, fotoperíodo e temperatura no estabelecimento in vitro de jabuticabeira. Scientia Agraria, v. 8, n. 1, p. 19-23, 2007.

28. RADHIKA, K. et al. Thidiazuron stimulates adventitious shoot regeneration in different safflower explants. Biologia Plantarum, v. 50, n. 2, p. 174-179. 2006.

29. RIBAS, L. et al. Estabelecimento de culturas assépticas de Aspidosperma polyneuron. Ciência Florestal, v. 13, n. 1, p $115-122,2003$

30. ROCHA, P. et al. Multiplicação e alongamento in vitro do porta-enxerto de Prunus. Journal of Biosciences, v. 25, n. 1 , p. $69-74,2009$

31. SAMPAIO, P. T. B. Sumaúma, Ceiba pentandra. In: CLAY, J. W.; SAMPAIO, P. T. B.; CLEMENT, C. R. (Eds.) Biodiversidade Amazônica: exemplos e estratégias de utilização. Manaus: Serviço Brasileiro de Apoio à Pequena e Média Empresa, 1999. p. 7-41.

32. SKIRVIN, R. et al. Establishment of contaminant-free perennial plants in vitro. In Vitro Cellular and Development Biology - Plant, v. 35, n. 4, p. 278-280, 1999.

33. SUBOTIE, A. et al. Effect of urea and type of citokinins on axillary shoots regeneration of Impatiens walleriana $\mathrm{L}$. Biotechnology \& Biotechnological Equipment, v. 22, n. 3, p. 817-819, 2008.

34. TAIZ, L.; ZEIGER, E. Fisiologia vegetal. 4. ed. Porto Alegre: Artmed, 2008. $719 \mathrm{p}$

35. TORRES, A. C.; TEIXEIRA, S. L.; POZZER, L. Cultura de ápices caulinares e recuperação de plantas livres de vírus. In: TORRES, A.C.; CALDAS, L.S. ; BUSO, J.A. de (Eds.). Cultura de tecidos e transformação genética de plantas Brasília: EMBRAPA, 1998. p. 133.

Recebido em 02/12/2009 Aceito em 29/11/2010 
